\title{
Los derechos humanos y la justicia distributiva trasnacional
}

\author{
J. PAUL MARTIN*
}

\begin{abstract}
SUMARIO: I. DEBATES CONTEMPORÁNEOS.- II. UNA DEFINICIÓN DE TRABAJO.- III. LA NATURALEZA DE LA OBLIGACIÓN: TEORÍAS DE LA JUSTICIA DISTRIBUTIVA TRANSNACIONAL.- IV. LA NATURALEZA DE LA OBLIGACIÓN: EL RÉGIMEN INTERNACIONAL DE LOS DERECHOS HUMANOS.- V. CUMPLIENDO LA OBLIGACIÓN: LAS ORGANIZACIONES INTERNACIONALES.- VI. ¿EXISTE UN CONSENSO INTERNACIONAL?
\end{abstract}

\section{DEBATES CONTEMPORÁNEOS}

El propósito del presente artículo es hacer un seguimiento a la trayectoria del pensamiento reciente en los campos de la teoría moral y los derechos humanos internacionales con respecto a la justicia distributiva transnacional ${ }^{1}$. Las preguntas que se plantean son las siguientes: ihasta qué punto los principios, estrategias e instituciones en ambos campos proporcionan la base para un régimen de la justicia distributiva trasnacional que permitiría demandas extraterritoriales en casos de privaciones importantes de los derechos a la supervivencia? ${ }^{2} \mathrm{Y}$, si es así, icómo podría implementarse dicho régimen? Argumentaré que, si bien el régimen de los derechos humanos y las teorías de la justicia distributiva abordan algunos de los mismos problemas y si bien los pensadores sobre la justicia distributiva demandan cada vez más las obligaciones trasnacionales, el régimen de los derechos humanos no ofrece una base para las obligaciones de la justicia distributiva como tal. Las razones reflejan más una voluntad política y económica que un argumento moral o legal. No obstante, existe una institución internacional clave en favor de su misión principal establecida de aliviar la pobreza, incluso si ha evitado solícitamente integrar los principios de los derechos humanos en sus políticas y práctica, que es, a saber, el Banco Mundial33.

* CatedráticoydirectordelosEstudiosdeDerechosHumanosdelBarnardCollege,UniversidaddeColumbia. Agradezco la asistencia en la investigación brindada por Kyusun Rose Chung, del Columbia College.

1 He elegido el término justicia «transnacional» y no «internacional» para enfatizar la dinámica de los intercambios y relaciones, en vez de una mera esfera de la actividad.

2 Las demandas extraterritoriales han sido examinados en SKogly, Sigrun I. y Mark Giвney. «Economic Rights and Extraterritorial Obligations». En Shareen Hertel y Lanse Minkler. Economic Rights: Conceptual, Measurement, AndPolicylssues.Cambridge:CambridgeUniversityPress,2007,pp.267-283.Ellosconcluyen que, si bien las obligaciones primarias yacen en el gobierno nacional, los otros Estados están obligados a haceralgo más que «apoyar,» yagregan que, sobrelabase delartículo28 de la Declaración Universal de los Derechos Humanos(DUDH), el Derecho internacional les exigeque sean parte de un sistema internacional coordinado para respaldar el cumplimiento de, por ejemplo, el derecho a la alimentación (p. 281).

3 Véase BrodnIK, Gernot. «The World Bank and Human Rights: mission impossible? ». Harvard, Documento de Trabajo sobre la Política de Derechos Humanos del Centro Carr, T-01-05. En: <http://www.hks.harvard. edu/cchrp/Web\%20Working\%20Papers/BrodnigHR\&WorldBank.pdf>. 
La justicia trasnacional distributiva es un subcampo dentro de la justicia distributiva. Se cuestiona si los Estados tienen obligaciones con respecto a la distribución relativa de la riqueza sobre otros Estados, pueblos o individuos fuera de su jurisdicción territorial. Dichas obligaciones serían análogas al tratado y a las obligaciones legales locales que los Estados reconocen con respecto a las personas que viven dentro de su jurisdicción. En el Derecho internacional, estas obligaciones internas constituyen obligaciones calificadas, mas no absolutas. Se formulan en el artículo 2 del Pacto de las Naciones Unidas de los Derechos Económicos, Sociales y Culturales como la obligación de cada Estado signatario (aproximadamente 160 al escribir este ensayo) «a adoptar medidas, tanto por separado como mediante la asistencia y la cooperación internacionales, especialmente económicas y técnicas, hasta el máximo de los recursos de que disponga, para lograr progresivamente, por todos los medios apropiados, inclusive en particular la adopción de medidas legislativas, la plena efectividad de los derechos aquí reconocidos». ¿Podrían tener los países (ricos) obligaciones similares con las personas dentro de otros Estados (pobres)?

En la ONU, los debates sobre las obligaciones de los Estados ricos frente a los Estados pobres alcanzaron cierta intensidad antes y después de la aprobación, en 1986, de la Declaración sobre el Derecho al Desarrollo de las Naciones Unidas. Hoy en día, este asunto se enfoca en las estrategias para eliminar la pobreza frente a la división entre los extremadamente ricos y los extremadamente pobres. Las preguntas relacionadas con este tema abordan los principios que deberían gobernar la distribución de la riqueza generada por las empresas comerciales en los países de bajos ingresos y si existe alguna obligación transnacional generada por las diferencias, en todo el mundo así como dentro de los Estados, con respecto al acceso a las necesidades básicas de supervivencia, tales como el acceso al agua limpia y a los alimentos, a la atención médica y a la educación necesaria para sobrevivir en el mundo moderno. Como en los años ochenta, estas preocupaciones plantean preguntas sobre la justicia distributiva transnacional, especialmente sobre si las naciones con mucho tienen una obligación de ayudar a quienes no tienen nada. Como se sugiere arriba, este examen busca obligaciones más calificadas que absolutas, obligaciones que podrían (a) incorporar las calificaciones similares a la fórmula de arriba, presente en el pacto, y (b) limitar las demandas a las poblaciones verdaderamente necesitadas de los Estados que no pueden satisfacer las obligaciones del pacto.

Dicha obligación calificada debe ser consistente con los requerimientos básicos de los derechos humanos, especialmente en el hecho de que son universales e innatos. El derecho a la vida (supervivencia) ${ }^{4}$, por ejemplo, es visto como la base fundamental de los demás derechos humanos que 
han sido endosados por los Estados del mundo como universales en importancia, demandas que deben ser aseguradas por toda la humanidad. De esta forma, si el derecho a la vida/supervivencia es verdaderamente un derecho humano que todos los seres humanos poseen, no puede ser atropellado o anulado por factores transitorios tales como los límites geográficos o la conceptualización del Estado y las relaciones entre los Estados en un punto determinado en el tiempo. Sin embargo, no todos los derechos humanos son iguales. Por ello, tampoco lo son las obligaciones relacionadas a estos; ellas variarán en relación con las medidas necesarias para asegurar su cumplimiento. Asegurar el derecho a la vida, por ejemplo, es una obligación más alta y que requiere mayores esfuerzos que, por ejemplo, asegurar el derecho a la recreación. En el contexto de la justicia distributiva transnacional, los medios y los resultados podrían también ser calificados en el sentido de que ni sus medios ni sus resultados requieren de igualdad o de una distribución equitativa, sino simplemente satisfacer las necesidades básicas para sobrevivir como ser humano. Por ello, no requiere todo lo que es necesario para incluso una vida humana decente ${ }^{5}$. Esta valla más alta le añadiría consideraciones más disputadas, tales como definiciones culturales y geográficas distintas de lo que se requeriría según el término decente.

\section{UNA DEFINICIÓN DE TRABAJO}

Lo arriba mencionado contiene los elementos de una definición inicial de la justicia transicional, en especial una definición que es lo suficientemente amplia como para ser aceptada de manera general, una que incluya los elementos morales y legales centrales, sin ser demasiado dependientes de cualquier tradición cultural o intelectual única. Con esto en mente, y buscando eliminar cualquier premisa, defensa, detalles o consecuencias filosóficas y jurisprudenciales que reducirían su aplicabilidad universal, elegimos comenzar con la siguiente definición: la justicia distributiva transnacional es un campo de investigación y una práctica que aborda las obligaciones extraterritoriales de los Estados con respecto a la distribución de todas las formas de riqueza y cargas dentro de un sistema social determinado.

Los elementos importantes de esta definición son:

- Primero, reconoce la distinción entre la justicia distributiva como un fin o una meta común y los medios - a menudo bastante diversos - que se utilizan para alcanzar dicha meta. Así, a causa de su diversidad, los medios no se incluyen en la definición.

- Segundo, afirma la cualidad básica de cualquier demanda de justicia; especialmente, coloca una obligación correspondiente y un 
sujeto del deber. No se trata tan solo de una afirmación de buena voluntad ${ }^{6}$.

- Tercero, la definición no define las bases de la obligación que, legítimamente, puede variar de sociedad en sociedad, así como de pensador en pensador.

Algunas de estas bases, razones y teorías se examinarán en los siguientes párrafos.

\section{LA NATURALEZA DE LA OBLIGACIÓN:TEORÍAS DE LA JUSTICIA DISTRIBUTIVA TRANSNACIONAL}

La existencia de una obligación sobre los países ricos es obvia en la política de los países pobres y sus gobiernos. Los pensadores similares en la tradición socialista tienen poca dificultad para justificar la distribución de la riqueza. Por ello, esta sección sobre las teorías de la justicia distributiva transnacional estará dedicada completamente a los pensadores del mundo más rico, ya que estos son los Estados que se resisten a la idea de que exista una obligación transnacional.

Si bien los derechos humanos y la justicia distributiva han sido campos distintos, cada vez más pensadores abarcan ambos campos. Entre ellos está Stanley Hoffman, quien en su estudio de 1981, Ética más allá de las fronteras ${ }^{7}$, plantea las siguientes preguntas: iexisten obligaciones entre las naciones ricas y pobres, comparables con las que la mayoría de sociedades locales acepta hacia los miembros más pobres de dichas sociedades? Si existen tales obligaciones, icuál es su destino? iSon adeudadas a los gobiernos? ¿O a los individuos en dichos países más pobres? Él responde a estas preguntas en el contexto de la política exterior de los Estados Unidos, y enfatiza la necesidad de que existan políticas que consideren los probables resultados, así como sus metas, medios y estrategias. Está más interesado en cómo cumplir la obligación para ayudar que en la naturaleza de la obligación moral o legal. Sus recomendaciones aceptan una obligación extraterritorial moral general, pero no legal, y son de tono pragmático:

Ante la ausencia de las instituciones supranacionales y del consenso transnacional, las políticas internacionales de la justicia distributiva están confinadas a ser frustrantes - el resultado de duros regateos entre los Estados para quienes el poder o el estatus son ciertamente tan importantes como la justicia, y de la competencia entre dos bandos de reformadores bien intencionados tratando de alcanzar a los pobres más allá de las barreras de las fronteras de los Estados y los gobiernos


any human rights? Daedalus, 112, 1983, pp. 1-17.

7 Hoffman, Stanley. Duties beyond borders: On the Limits and Possibilities of Ethical International Politics. Syracuse: Syracuse University Press, 1981, p. 6. 
deseosos de preservar tanto la independencia de su nación como su base de poder interno ${ }^{8}$.

En este análisis temprano, los derechos humanos internacionales tienen un perfil bajo en favor del realismo basado en la preocupación moral.

El teórico canadiense sobre la paz, Johan Galtung, en su libro de 1994 Los derechos humanos en otra clave, también abordó el problema de la redistribución internacional de la riqueza en el contexto de los debates de los años ochenta y noventa sobre crear un nuevo orden económico internacional (NOEI). Se enfocó en el cambio sistémico en contraposición con el cambio local. Favorece el concepto del NOEI sobre la base de que puede ser utilizado para forjar Estados sólidos y de que la «estructura que podría utilizarse para redistribuir la riqueza internamente, tal como la atención médica gratuita, la educación gratuita y el transporte subsidiado, mejores condiciones de intercambio de bienes producidos en el campo y los bienes producidos en las ciudades, etcétera». Sin embargo, él no prevé que suceda esta redistribución dado el tipo de condiciones que se habían establecido entonces en el Fondo Monetario Internacional ${ }^{9}$. Concluye, por ello, que un orden tal como el del NOEI no es condición suficiente para satisfacer las necesidades de los pobres ${ }^{10}$. Su análisis también aborda el impacto de las políticas económicas globales y el papel interno, doméstico, del Estado, en vez de las obligaciones de los demás Estados o de la comunidad internacional con respecto a la justicia distributiva.

John Rawls, en El derecho de los pueblos ${ }^{11}$, publicado en 1999, basó su teoría de la justicia internacional o cosmopolita en la jerarquía societal de los «pueblos» del mundo, encabezada arriba por las sociedades bien ordenadas o pueblos liberales que aceptaran la supremacía del Derecho sobre la base de los principios de igualdad, libertad y tolerancia ${ }^{12}$. En el segundo nivel, coloca a aquellas sociedades que son «razonables», «gente decente» y justa, que poseen órdenes políticos decentes, pero que en cierta manera tienen defectos, tales como el no aceptar la diversidad religiosa. En el tercer nivel están los «Estados fuera de la ley»; en el cuarto, las sociedades agobiadas por condiciones desfavorables y, en el quinto, los «absolutismos benevolentes», sociedades que «honran los derechos humanos, pero, debido a que a sus miembros se les niega un papel significativo en las decisiones políticas, no están bien ordenados». Los Estados fuera de la ley son tiránicos o despóticos, y por ello fuera de la ley, sobre la base de que no sirven a los mejores intereses de sus pueblos. A pesar de que esta es más una tipología que una jerarquía, resulta

8 Ibid., p.185.

9 Ibid.

10 Galtung, Johan. Human Rights in another key. Cambridge: Polity Press, 1994, p. 94.

11 Rawls, John. The Law of Peoples. Cambridge: Harvard University Press, 1999. Para encontrar un análisis del pensamiento de Rawls sobreesteaspecto, véase KoKAz, Nancy. «Poverty and global justice». Ethics and International Affairs, 21, 3, 2007, pp. 317-336.

12 Véase The Law of Peoples. Op. cit., p. 4 y ss.; Pettrt, Philip. «Rawls's peoples». En Rex Martin y David A. Reidy (editores). Rawls's Law of Peoples: A Realistic Utopia?New York: Blackwell, 2006. (En adelante, Martin y Reidy).

LOS DERECHOS HUMANOSY LA JUSTICIA DISTRIBUTIVA TRASNACIONAL 
ser una jerarquía tripartita. También es la base para las obligaciones por parte del primer grupo a asistir a las sociedades «oprimidas», especialmente a aquellas que sufren «condiciones desfavorables». Esto se define como el «derecho de asistencia» en todos los pueblos bien ordenados y se agregó en la edición posterior de 1999 de El derecho de los pueblos. Al definirlo como un derecho, sienta una sólida base para la justicia distributiva transnacional. Sin embargo, al basar su argumento en una teoría de los pueblos y en una visión liberal y jerárquica del mundo, así como en una lista de derechos básicos que prácticamente excluye los derechos económicos y sociales ${ }^{13}$, es poco probable que Rawls movilice intelectual o políticamente a quienes no se suscriben a su visión del mundo.

Un antiguo estudiante de Rawls y ahora catedrático de Yale, Thomas Pogge, lo censura por esta visión de la sociedad jerárquica y basada en los pueblos ${ }^{14}$. Pogge basa sus argumentos en favor de una redistribución de la riqueza en el valor moral, que es igual para cada ser humano individual. La pobreza es vista categóricamente como un déficit de los derechos humanos. Ayudar a los pobres es un imperativo moral. La obligación moral asignada a los ricos no es solamente la de no hacer daño -lo que Pogge aborda también largamenteen el mundo empobrecido. Esta obligación se deriva en parte de la obligación de remediar los errores pasados, principalmente la explotación histórica de los países más pobres por parte de los países más ricos. Un trabajo posterior de Pogge ha buscado definir los costos y mecanismos para implementar una redistribución de la riqueza de las comunidades ricas hacia las pobres.

Tal vez nadie más que Amartya Sen, el economista y filósofo indio, le ha prestado mayor atención al alivio de la pobreza. Su análisis de hambrunas como las de Bengal (1943), de la cual él fue testigo personal cuando era niño, Irlanda (década de 1840), Etiopía (años setenta), Ucrania (años cuarenta), China (años cincuenta) y Bangladesh (1974) lo llevaron a enfatizar el papel que desempeñan las instituciones democráticas para prevenirlas. Identificó un gobierno especialmente responsable, una prensa libre y la preparación para implementar las medidas de emergencia como factores que pueden superar las deficiencias en el mercado de empleos y bienes que pueden conducir a la hambruna ${ }^{15}$. Sin embargo, su análisis no se enfoca en la justicia distributiva transnacional como tal. Las hambrunas pueden ser enfoques evitados por parte del Estado individual y la efectividad de sus instituciones. Él subraya la importancia de las libertades políticas y las oportunidades sociales, así como la agencia libre y sostenible por parte de aquellos que gozarían de estas libertades y oportunidades ${ }^{16}$. Esta dimensión se replica en su posterior trabajo sobre

13 MILLER, David. "Collective responsability and International Inequality in The Law of Peoples». En Martin y Reidy.Op.cit.,p.194. Además, MARTIN, Rex. «Rawlson InternationalDistributiveEconomic Justice:Takinga closer look». Ibid., p. 227.

14 Véase Pogge, Thomas. «Do Rawls's Two Theories of Justice Fit Together?». Ibid., pp. 206.

15 Sen, Amartya. Development as freedom. Nueva York: Alfred P. Knopf, 1999.

16 Ibid., p. 11. 
el desarrollo —-definido como la expansión de las libertades reales que gozan las personas- y los derechos humanos. Aborda la inequidad y el marco de los derechos de manera extensa, mas no la existencia o la naturaleza de las obligaciones internacionales de los $\operatorname{Estados}^{17}$. A pesar de que define tanto los mercados del empleo como los de los bienes como procesos globales y reconoce la necesidad de una asistencia internacional para aliviar el hambre, él no argumenta que esto pueda imponer una obligación legal o moral extraterritorial a los Estados.

Juntos, los análisis anteriores brindan muchos de los elementos necesarios para lograr una teoría más inclusiva de la justicia distributiva transnacional. Sen enfatiza el rol interno clave de cada Estado y la importancia de asegurar la participación libre y sostenida del pueblo en la búsqueda del desarrollo. Pogge promueve una teoría de la obligación moral internacional que aborda tanto metas como medios. Hoffman se basa en las premisas morales pero enfatiza la relevancia de las consideraciones prácticas, especialmente, ifuncionará? El mensaje de Rawls parece tener menos que ofrecer al brindar un análisis social basado en el liberalismo occidental, y por ello resulta poco probable que atraiga el consenso internacional. Hoffman enfatiza la necesidad de un realismo que reconozca que cualquier sistema de justicia distributiva transnacional depende de los Estados y de un mundo con fuerzas económicas y políticas globales poderosas sobre las que los Estados individuales disfruten distintos niveles de control. Galtung hace eco de esto: argumenta que el cambio sistémico es esencial. En sus teorías falta un enfoque para abordar los problemas relacionados a que los Estados, con sus asimetrías relativas del poder, no son solamente los actores principales sino los legisladores del sistema global. Los Estados crean el Derecho internacional, incluyendo la ley sobre los derechos humanos, así como las leyes políticas y prácticas que gobiernan de facto la distribución internacional de la riqueza, especialmente mediante instituciones internacionales claves como el Banco Mundial y la Organización Mundial del Comercio.

\section{LA NATURALEZA DE LA OBLIGACIÓN: EL RÉGIMEN INTERNACIONAL DE LOS DERECHOS HUMANOS}

El cuerpo de los derechos humanos internacionales fue formulado por primera vez y de manera más completa en 1948 bajo la forma de la Declaración Universal de los Derechos Humanos (DUDH). Desde entonces, el alcance del cuerpo ha sido afinado continuamente en respuesta a los nuevos retos. Sigue siendo un trabajo en marcha. La DUDH nació en el mundo de la posguerra: los abusos más conspicuos de los derechos humanos fueron los de la Alemania nazi y la Segunda Guerra Mundial, durante la cual los abusos parecen haber conducido, precisamente, a la guerra. Durante los años cincuenta y sesenta, la descolonización y 
el totalitarismo socialista constituyeron los primeros puntos de referencia. Hoy en día, la imagen más extendida de los abusos de los derechos humanos parece ser la pobreza de un amplio segmento de la población mundial, como resultado de una distribución bastante dispareja de la riqueza del mundo. Esta conciencia ha sostenido debates sobre si existen obligaciones de naturaleza legal y/o ética y universal apremiantes que requieren que se rectifiquen los actuales patrones de acceso a la riqueza. Esta sección examina esta cuestión desde el punto de vista de las leyes y prácticas existentes de los derechos humanos internacionales.

A pesar de la evolución del consenso internacional con respecto a los principios y las prácticas de los derechos humanos que han tenido lugar desde que la ONU aprobó la DUDH, en 1948, el régimen aún tiene sus críticos. Una crítica flexible teórica y práctica es el argumento de que los derechos no pueden existir sin una seguridad razonable que estos puedan garantizarse. El actual régimen internacional de derechos humanos establece que los Estados parte de los diversos tratados son los principales garantes de los derechos contenidos en cada instrumento. Así, la realización de los derechos humanos verdaderamente internacionales y verdaderamente universales depende principalmente de cada Estado individual. En la práctica, algunos Estados cuentan con los recursos para garantizar la mayoría de los derechos dentro de sus territorios, mientras que otros tienen una capacidad o incluso una voluntad bastante limitadas para garantizarlos o protegerlos. ¿Qué ofrece el actual régimen de los derechos humanos a manera de remedios cuando los Estados individuales son seriamente deficientes en asegurar estos derechos dentro de sus territorios?

El régimen moderno de los derechos humanos los define como las condiciones mínimas para la dignidad humana que todos los gobiernos deben respetar, proteger y cumplir. Violaciones graves de estos dentro de un Estado son reconocidas como una preocupación legítima de la comunidad internacional. Si la situación amenaza a otros países, la seguridad internacional también podría ser cuestionada y la situación se convierte entonces en una preocupación para el Consejo de Seguridad. Antes del final del apartheid y de la Europa comunista en 1989, los derechos civiles y políticos fueron el escenario central que impulsó el llamado a la acción internacional. Entre los casos que atrajeron la preocupación internacional, tenemos a Sudáfrica, Chile, Israel y los Territorios Ocupados y la antigua Yugoslavia. Hoy en día, el enfoque se ha expandido para incluir los derechos económicos y sociales. No obstante, al responder a las violaciones serias asociadas con el derecho a la vida ocasionadas por hambrunas o pobreza, tales como las sucedidas en Darfur o Zimbabwe, los llamados actuales a la acción internacional tienden a ser predicados por las amenazas a la seguridad regional o colectiva ${ }^{18}$, en vez del verdadero sufrimiento humano. 
Al buscar traer la justicia distributiva a la arena internacional, Thomas Pogge ${ }^{19}$ se vuelve al artículo 28 de la DUDH —un documento aceptado actualmente como Derecho consuetudinario- para argumentar que la implementación de los derechos humanos requiere acción intergubernamental. El artículo 28 dice: «Toda persona tiene derecho a que se establezca un orden social e internacional en el que los derechos y libertades proclamados en esta Declaración se hagan plenamente efectivos». Esto, él argumenta, constituye la base para las demandas sobre el orden global o la estructura institucional que debería asegurar un sistema social amplio que garantice que todos los seres humanos gocen del acceso seguro a sus propios derechos humanos. Para él, el artículo 18 le pide a «todos los ciudadanos y gobiernos de los Estados desarrollados [...] que apoyen las reformas institucionales en favor de un orden global que respaldaría fuertemente la emergencia y estabilidad de los regímenes democráticos, respetuosos de los derechos humanos y pacíficos y que también tiendan a reducir las privaciones y desigualdades económicas radicales». Su argumento también se basa en la evaluación empírica del impacto de facto que tienen los sistemas globales sobre los derechos humanos y en el hecho de que estos sistemas estén bajo el control de la comunidad internacional y que puedan ser cambiados por ella. Él enfoca su demanda en mejorar los sistemas globales y en organizar un orden económico global, en lugar de la obligación de los Estados individuales ${ }^{20}$.

El Derecho existente sobre los derechos humanos sí brinda al menos un ejemplo en el que se ha requerido a los Estados responder a los abusos de los derechos humanos fuera de sus fronteras, a pesar de que ninguno de sus sujetos esté involucrado ni como perpetrador ni como abusado. Es el caso del genocidio, un crimen que los Estados firmantes de la Convención Internacional para la Prevención y la Sanción del Crimen de Genocidio se comprometen a evitar y castigar ${ }^{21}$. Los Estados firmantes asumen así sus obligaciones más allá de sus fronteras. Sin embargo, como hemos visto en el caso de Ruanda, se ha comprobado que es difícil forzar a los Estados a aceptar esta obligación de evitar y castigar por su propia cuenta, cuando no es visto, además, como una amenaza a la seguridad regional o a su propia seguridad. El Pacto de los Derechos Económicos, Sociales y Culturales ofrece poco bajo la forma de las obligaciones extraterritoriales de los Estados, sin hablar de «prevenir» o «castigar» a los Estados errantes. El pacto de 1966 obliga a los Estados signatarios solamente con respecto a quienes están dentro de sus territorios, y en ese caso solo para promover o alcanzar, progresivamente y sin discriminación, derechos tales como a la educación, al trabajo, a la salud, a la seguridad social y a un estándar de vida adecuado (alimentación,

19 Pogge, Thomas. «El significado internacional de los derechos humanos». Revista de Ética, 4, 1999, pp. 4569.

20 Véase, porejemplo,Pogge,Thomas. «Erradicandolapobrezasistémica; alegatoafavordelosdividendosde los recursos globales". Revista sobre el Desarrollo Humano, 2, 1, 2001, pp. 59-77.

21 ArtículoprimerodelaConvenciónInternacionalparalaPrevenciónylaSancióndelCrimendeGenocidio,que entró en vigencia el 12 de enero de 1951. 
vestimenta y condiciones de vida). La naturaleza de estas obligaciones domésticas de los gobiernos ha sido y continúa siendo explorada extensamente por los Comentarios Generales del Comité del Tratado, avivados por la sociedad civil internacional ${ }^{22}$. Uno de los retos subyacentes, incluso dentro de la esfera doméstica, es la ejecución y especialmente la justiciabilidad de los derechos económicos y sociales. Debido a razones que varían de un sistema político a otro, los mecanismos de ejecución y los precedentes legales han seguido siendo inferiores para la mayoría de los derechos civiles y políticos. Este compromiso más débil se replica en el sistema internacional.

Al trabajar para formular la Declaración de las Naciones Unidas sobre el Derecho al Desarrollo de 1986, las naciones más pobres no tuvieron éxito en su búsqueda por definir e incorporar en la declaración las obligaciones transnacionales sobre los Estados, en especial, las obligaciones sobre los Estados más ricos de ayudar a los Estados empobrecidos. En el artículo 1, la declaración define el derecho al desarrollo sin un sujeto del deber. El desarrollo es «un derecho humano inalienable en virtud del cual todo ser humano y todos los pueblos están facultados para participar en un desarrollo económico, social, cultural y político, en el que puedan realizarse plenamente todos los derechos humanos y las libertades fundamentales, a contribuir a ese desarrollo y a disfrutar de él».

Como tal, este derecho define un polo de la justicia distributiva, especialmente el derecho de todos los individuos y los pueblos a disfrutar y compartir el desarrollo social, cultural y político. El otro polo, la obligación de promover y asegurar este derecho es asignada más adelante en el documento a los Estados individuales y no a la comunidad internacional. Los subsiguientes artículos urgen a los Estados a formular las políticas apropiadas de desarrollo nacional y a crear las condiciones nacionales e internacionales favorables para la realización del derecho al desarrollo. Por ejemplo, en el artículo 3 se lee lo siguiente: «Los Estados deben realizar sus derechos y sus deberes de modo que promuevan un nuevo orden económico internacional basado en la igualdad soberana, la interdependencia, el interés común y la cooperación entre todos los Estados, y que fomenten la observancia y el disfrute de los derechos humanos»; y en el artículo 4: «Los Estados tienen el deber de adoptar, individual y colectivamente, medidas para formular políticas adecuadas de desarrollo internacional a fin de facilitar la plena realización del derecho al desarrollo».

El artículo final 10 repite los temas generales de la declaración: «Deben adoptarse medidas para asegurar el pleno ejercicio y la consolidación progresiva del derecho al desarrollo, inclusive la formulación, adopción 
y aplicación de medidas políticas, legislativas y de otra índole en el plano nacional e internacional».

Los conceptos de la justicia transnacional se dejan al lenguaje motivador del preámbulo, que urge una acción de remedio mediante la cooperación y las relaciones amigables entre los Estados, la distribución justa de los beneficios, evitar el colonialismo, el neocolonialismo y las amenazas a la soberanía nacional, asegurar la igualdad de oportunidades y la necesidad de un nuevo orden económico internacional.

Este alejamiento entre Estados ricos y pobres continúa siendo la actual postura en las Naciones Unidas. Bertrand Ramcharan, el antiguo alto comisionado interino para los Derechos Humanos de la ONU, en su libro de 2008 Ideas contemporáneas sobre los derechos humanos ${ }^{23}$, escribe que el Movimiento de los No Alineados aún busca un tratado, no solamente una declaración, sobre el derecho al desarrollo que utilizaría el lenguaje que afirma el deber de los Estados de crear condiciones que conduzcan a la realización del derecho al desarrollo y para la cooperación que no esté condicionada ni que sea tratada como caridad. La respuesta de la Unión Europea, los Estados Unidos, Canadá y otros, él relata, es afirmar el derecho al desarrollo pero continuar limitando las obligaciones de los Estados individuales a aquellas dentro de su territorio. Dichas partes siguen oponiéndose a un documento legalmente vinculante sobre el derecho al desarrollo que incorporaría las obligaciones transnacionales demandadas por el Movimiento de los No Alineados.

Parece poco probable que los países más ricos admitan pronto cualquier obligación de ayudar a los países pobres que no sea en términos vagos sobre un orden económico general y una cooperación prometedora. A pesar de que el preámbulo del Pacto sobre los Derechos Económicos, Sociales y Culturales afirma los derechos igualitarios e inalienables de todos los miembros de la familia humana, y de que estos derechos se derivan de la dignidad inherente de la persona humana, y de que el artículo 1 afirma que ninguna persona puede ser privada de sus propios medios de subsistencia, no existe una obligación de ayudar entre los demás Estados. El lenguaje sigue refiriéndose a la cooperación. Cualquier ayuda debe ser considerada como de naturaleza humanitaria, esto es, por buena voluntad, o de acuerdo con los intereses de la seguridad nacional o colectiva, tal como en los casos de una epidemia de salud o un conflicto violento. El artículo 11 del Pacto sobre los Derechos Económicos, Sociales y Culturales plantea explícitamente que dicha cooperación internacional debería «basarse en el libre consentimiento», y excluir cualquier idea de que sea obligatoria.

Al final, los obstáculos para que los Estados acepten las obligaciones de la justicia transnacional tienen dos aspectos: la doctrina de la soberanía nacional, y el estatus relativo de los principios y prácticas con respecto a 
los derechos económicos y sociales en contraposición con los derechos civiles y políticos. De hecho, la legislación internacional de los derechos humanos, si bien en algunos aspectos infringe la soberanía nacional, en otros la privilegia, en la medida en que las fronteras geográficas, las filosofías políticas y los recursos económicos de los Estados determinan el grado en el que los derechos humanos serán o no protegidos y realizados. Las obligaciones de los derechos humanos parecen terminar en los límites de un Estado. El Estado y la soberanía del Estado, en gran medida edificaciones humanas en contraste con los derechos humanos que son definidos como innatos, atropellan las demandas de universalidad de estos últimos. Si estos dos obstáculos siguen constituyendo un impasse, iexisten otras opciones? Esto nos hace regresar a las ideas de algunos de los teóricos de la justicia distributiva transnacional con respecto al papel de las instituciones internacionales y de algunas de sus acciones que están sentando precedentes en la práctica con respecto a la justicia distributiva.

Se puede promover la expansión del papel de las agencias intergubernamentales sobre la base de un argumento teórico, especialmente por el hecho de que si los derechos humanos son innatos y universales, entonces los derechos de todos los seres humanos no se pierden cuando falla su principal garante. Si la geografía, la política estatal y la pobreza no vencen de esta manera las demandas por los derechos humanos, se plantea la posibilidad de que la obligación y la carga del deber recaigan en la comunidad internacional, a pesar de que puedan no ser bienvenidas. En otras palabras, las demandas por las principales violaciones a los derechos humanos y sus obligaciones relacionadas, ya sea en los campos de los derechos civiles y políticos o económicos, sociales y culturales, se extienden legítimamente más allá de las fronteras del Estado.

De esta manera, una falla seria por parte de un Estado individual de garantizar los derechos básicos de quienes viven dentro de su jurisdicción resultaría en una obligación por parte de la comunidad internacional, empezando por el hecho de que se trata de la principal legisladora y de quien hace cumplir los instrumentos que denominamos la Declaración Internacional de los Derechos. Para seguir con esta línea de pensamiento, podemos mirar las prácticas recientes de algunas de las organizaciones internacionales, especialmente del PNUD y del Banco Mundial.

\section{CUMPLIENDOLAOBLIGACIÓN: LASORGANIZACIONES INTERNACIONALES}

En el contexto del desarrollo, Amartya Sen ha señalado que los derechos humanos son a la vez metas y medios para alcanzar el desarrollo político y económico. Lo mismo podría decirse de la justicia distributiva. Funciona tanto como meta y como medio. Por otro lado, los fines y los medios no deberían confundirse o fusionarse. Una cosa es postular una 
meta, en este caso la obligación de aliviar la pobreza, y otra definir e implementar los mejores medios para alcanzarla. La implementación de proyectos tan complejos como el alivio de la pobreza requiere cadenas de muchos eslabones efectivos, especialmente de los recursos financieros necesarios, de las sociedades institucionales necesarias, de estrategias y planificación efectiva, y de la voluntad y la motivación políticas por parte de todos los actores para alcanzar las metas. En el caso de la justicia distributiva transnacional, las cadenas empiezan con las instituciones internacionales con voluntad para llevar esto a cabo y dependen sustancialmente de ellas.

Thomas Franck ${ }^{24}$ ha identificado una serie de formas en las que los principios asociados con la justicia distributiva internacional han influido en las decisiones por parte de los entes mundiales en favor de redistribuir la riqueza mediante regulaciones que tenían como resultado que los países más ricos compensaran a los más pobres —y en el proceso pasaran por encima de la soberanía nacional- ${ }^{25}$. Estas decisiones incluían afirmar y distribuir, a lo largo de tratados y otros procesos, los derechos de los países a disfrutar los recursos comunes, tales como el zócalo continental, los lechos del mar, el espacio exterior y otros aspectos del ambiente común. Él ancla estas decisiones en un compromiso sistémico con la justicia basada en los principios de legitimidad y equidad, en vez de en los derechos humanos como tales. Lamentablemente, aborda solo brevemente el contexto de la descripción de distintos programas de ayuda.

La justicia transnacional distributiva está adoptando formas diversas y casi informales en las operaciones de las Naciones Unidas y de las demás agencias internacionales, ya que cada una de ellas debe realizar provisiones generalmente aceptables para compartir los recursos comunes y crear las instituciones necesarias para administrarlas. Las actividades recientes de la ONU en el campo de la Responsabilidad Social Corporativa (RSC) podrían ser vistas como un caballo de Troya con respecto a la justicia transnacional distributiva. Una preocupación activa en dicho campo es la responsabilidad de las corporaciones grandes, típicamente occidentales, y ahora también las chinas e indias, que operan en los países de bajos ingresos. Algunas están vendiendo productos, ya sean hechos o patentados en otra parte; otros están brindando servicios tales como la seguridad o el agua y el saneamiento; mientras, otros están extrayendo minerales y demás recursos. En cada caso, las actividades corporativas pueden tener un impacto sustancial en las comunidades locales y las economías nacionales con respecto a la generación y a la distribución de la riqueza. iEn qué medida pueden los bienes y ganancias ser repatriados por agencias externas? ¿Cuánto se acumula para el país anfitrión? Comúnmente, el gobierno nacional administra la distribución de esta riqueza mediante los contratos que realiza con las corporaciones. 
El movimiento de la RSC busca hacer cumplir los códigos de conducta que gobiernan las acciones de las corporaciones en los países en desarrollo y, en el proceso, aborda las preguntas sobre la distribución de la riqueza generada por sus actividades.

Dos de los enfoques globales dentro del movimiento están representados por la agencia de la ONU sobre el compacto global y el relator especial de la ONU sobre los derechos empresariales y humanos, John Ruggie. A través de ellos, el movimiento de la responsabilidad social corporativa ha establecido exitosamente los principios para gobernar algunos aspectos de los negocios internacionales. En su más reciente informe (abril de 2009) al Consejo de Derechos Humanos de la ONU², titulado «Promoción de todos los derechos humanos, los derechos civiles, políticos, económicos, sociales y culturales, incluyendo los derechos al desarrollo», Ruggie busca poner en operación los principios y las prácticas de «proteger, respetar y remediar» los derechos empresariales y los derechos humanos. Él apoya su marco de trabajo en tres pilares: los deberes del Estado, basados en los tratados de proteger; la responsabilidad corporativa para respetar los derechos humanos; y un mayor acceso a los remedios efectivos por parte de las víctimas. Además, presenta un argumento en favor de una mayor cooperación internacional bajo la forma de la toma de conciencia, fortalecimiento de la capacidad y solución de problemas de manera conjunta. Lamentablemente, a pesar de que el informe urge una diligencia debida en todos lados, este, como otros códigos empresariales y procedimientos de monitoreo en el campo de la responsabilidad social corporativa, sigue implicando un proceso voluntario, con poco para hacer que las empresas respondan y sean responsables ante aquello que no represente tan solo un potencial daño a su imagen y su reputación.

En estricto contraste, la justicia distributiva en reversa entra en juego en el caso del enfoque de la Organización Mundial del Comercio frente a los derechos de la propiedad intelectual. El resultado neto de este proceso es asegurar que todos los que disfruten de los beneficios de un ítem dotado de derechos de propiedad intelectual obtengan las ganancias como corresponde. Este proceso goza de una estatura legal sólida en los convenios de la OMC del Acuerdo sobre los Aspectos de los Derechos de Propiedad Intelectual (ADPIC). Estos acuerdos protegen a los inventores intelectuales en tal medida que, como lo señala el filósofo Thomas Pogge, incluso la vida de los pacientes pobres debe acortarse para ajustarse a esto, en vez de todo lo contrario ${ }^{27}$. Los esfuerzos del movimiento de la RSC son entonces tigres de papel en comparación con los mecanismos para el cumplimiento instituidos por la OMC. Las políticas del ADPIC solamente pueden ser atropelladas por un Estado que invoca 
una emergencia nacional, tal como lo hicieron Brasil e India en su lucha contra el VIH/SIDA ${ }^{28}$.

En la práctica, el ADPIC supone el sistema más efectivo y que mejor se hace cumplir para asegurar la redistribución transnacional de la riqueza ${ }^{29}$. Lamentablemente, está diseñado para beneficiar a aquellos en el mundo industrial que son capaces de asegurar legalmente que se acumulen las ganancias por las invenciones en favor del dueño del diseño, la patente o el producto. Entonces, se requiere que inclusive los agricultores pobres en los países en desarrollo, sin un acuerdo que diga lo contrario, paguen honorarios adicionales para utilizar las semillas o los fertilizantes desarrollados en Occidente. Esto es cierto incluso si obtienen las semillas y fertilizantes de otras fuentes, e incluso si las semillas proviniesen de su cosecha del año anterior. Al hacer cumplir los derechos de los dueños de la propiedad intelectual, la OMS establece un ejemplo poderoso sobre el papel que pueden desempeñar las normas internacionales sobre la distribución de la riqueza.

Paralelamente a las actividades de la RSC y de la OMC, algunas instituciones financieras internacionales, especialmente el Banco Mundial, han buscado asegurar que la riqueza generada en los países pobres beneficie al país y en particular a sus pobres. Si bien las Naciones Unidas y muchas de sus agencias han incorporado los derechos humanos en su misión y operaciones, en lo que respecta a la eliminación de la pobreza, el Banco Mundial está en el centro del escenario debido a que la define como su principal misión. Ha establecido unidades internas enfocadas en los pobres, especialmente en la Justicia para los Pobres ${ }^{30}$ y las Voces de los Pobres ${ }^{31}$. La página web de las Voces, por ejemplo, señala haber recolectado las «voces» de más de 60 mil hombres y mujeres pobres de 60 países, en lo que denomina un esfuerzo sin precedentes para comprender la pobreza desde el punto de vista de los mismos pobres. Su página de Justicia para los Pobres anuncia:

La Misión del Banco es la reducción sostenida de la pobreza. La pobreza abarca la falta de oportunidades (incluyendo capacidades), la falta de voz y representación y la vulnerabilidad ante los shocks. El apoyo del Banco a la reducción de la pobreza se enfoca en acciones, consistentes con su mandato, para aumentar la oportunidad, realzar el empoderamiento y fortalecer la seguridad. Dentro de este marco amplio, una de las prioridades críticas es promover el crecimiento de una base amplia, dada su comprobada importancia para reducir la pobreza. 
La seriedad de este compromiso es subrayada por François Bourguignon, el economista en jefe del Banco Mundial, cuando escribió en 2005: «Es probable que el grado actual de desigualdad en el mundo entre los países sea la causa del conflicto social severo aún si éste existiese en un solo país» ${ }^{32}$. De esta manera, el Banco no trabaja bajo ilusiones con respecto a la seriedad de la situación.

Sin embargo, es difícil ver compromiso alguno con el análisis de los derechos humanos o un análisis basado en los derechos humanos del desarrollo económico y político en los principios y las prácticas del Banco. No existen argumentos de que la reducción de la pobreza se base en los derechos de los pobres. Cuando habla de justicia para los pobres, el concepto de justicia pertenece al proceso y no es sustantivo. En otras palabras, el Banco reconoce la importancia de «construir sistemas de justicia equitativa que se basen en las realidades culturales y sociales de los pobres y comprendan la justicia desde la perspectiva de los pobres ${ }^{33}$. Esta visión selectiva de los derechos humanos engaña el concepto y evita cualquier discusión de obligación, ya sea por parte del Banco o por parte de la comunidad internacional.

La literatura sobre el Banco y su relación con los derechos humanos internacionales es extensa y data de los años ochenta ${ }^{34}$. El Banco ha argumentado consistentemente que era una organización económica y no política, y que los derechos humanos y la manera en que el Estado trata a su propio pueblo son cuestiones políticas internas. Su posición refleja el hecho de que el Banco trata con los Estados y con sus representantes, y no con su pueblo. Presta a los Estados y solo ha reconocido ocasionalmente que los pueblos indígenas, por ejemplo, tienen intereses legítimos en los proyectos que este financia, que estos intereses podrían ser muy distintos e incluso estar en conflicto con los del Estado y, además, que estos pueblos no están bien equipados para representarse a sí mismos. Tales problemas fueron abordados por primera vez durante la participación del Banco en el esquema del río Narmada y otros esquemas para represas en la India ${ }^{35}$. No obstante, el Banco ha evitado solícitamente incorporar los derechos humanos internacionales en las metas, planificación e implementación de sus proyectos.

A pesar de los copiosos escritos de la sociedad civil que urgen al Banco a abrazar los derechos humanos, muy pocos Banco mismo. Los textos

32 «Distribuciónyredistribuciónglobal:unarevisiónpreliminar».DiscursoinauguralenlaConferenciadelBanco MundialsobrelaEconomíadelDesarrollode2005, quesepuedeencontraren<http://www.worldbank.icebox. ingenta.com/search;jsessionid=c4los0qjd7696?value1=world+bank+conference+2005\&option1=titleabstract $\&$ sort=score \&year_from $=1900 \&$ year_to $=2100 \&$ database $=1 \&$ search_type=quick $>$.

33 lbid.

34 Lawyers Committee for Human Rights. The World Bank Governance and Human Rights. Nueva York: Lawyers Committeefor Human Rights, 1995. También GILLIES, David. «Human rights, governanceanddemocracy:the World Bank's problem frontier». Netherlands Quarterly of Human Rights, 11,1, 1993, pp. 3-24.

35 Para obtener un informe reciente, véase «Efectividad en el desempeño y desarrollo del Proyecto Sarwar Sarovar ", del Instituto Tata de Ciencias Sociales, 2008, en <http://www.tiss.edu/SSP_Report.pdf>. FISHER, William F. (editor). Hacia el desarrollo sostenible, luchando por el río Narmada de la India. Armonk: M.E. Sharpe, 1995. 
originados en él, a diferencia de aquellos de los invitados a exponer en sus conferencias, principalmente muestran cómo su trabajo mejora los derechos humanos. Sin embargo, predica sus programas sobre dignidad humana y desea crear las condiciones necesarias para los derechos humanos ${ }^{36}$. En palabras del Banco, «proteger y promover los derechos humanos significa ayudar a las personas más pobres del mundo a escapar de la pobreza ${ }^{37}$. Le asigna la tarea de los derechos humanos a la responsabilidad de los gobiernos individuales y a la sociedad civil, a quienes el Banco urge a cumplir sus funciones. Se ve a sí mismo como un actor técnico y no político que confina sus actividades a las esferas de las finanzas, la economía y el desarrollo.

Esta teoría se observa en la práctica. Los proyectos individuales del Banco le prestan diversos niveles de atención a las necesidades de los pobres pero nunca desde la perspectiva de los derechos humanos. Un ejemplo fue el papel del Banco en el Proyecto Petrolero de Chad y Camerún, encabezado por Exxon, para el cual, a cambio de préstamos para permitir que los gobiernos de Chad y Camerún adquieran una participación en acciones del proyecto, obligaba al gobierno de Chad a aceptar asignar una porción de las ganancias del petróleo a una cuenta en custodia en Londres para ser utilizada exclusivamente para proyectos de bienestar social en Chad. Lamentablemente, el plan se evaporó cuando el gobierno decidió utilizar los fondos para defensa nacional. Si bien el préstamo del Banco era relativamente pequeño en comparación con la inversión de los tres socios liderados por Exxon, es difícil ver que el proyecto sea impulsado por la principal misión declarada por el Banco - principalmente, el alivio de la pobreza-, en oposición a beneficiarla esperanzadoramente. Ciertamente no hubo un intento abierto de incorporar los derechos humanos en el proyecto ni como principios guías ni para evaluar los resultados. Desde entonces, el proyecto ha hecho poco para aliviar los problemas de derechos humanos preexistentes, sin mencionar aquellos que se han presentado por la manera en que ha evolucionado el proyecto bajo el actual gobierno. La cuenta en custodia y sus proyectos de bienestar social ya no existen.

En contraste con el Banco Mundial, el Programa de las Naciones Unidas para el Desarrollo (PNUD) ha intentado incorporar los principios de los derechos humanos a todas sus políticas y prácticas, de manera especial en su Informe Anual del Desarrollo Humano de 2000 y en La reducción de la pobreza y los derechos humanos, una nota práctica, publicada en $2003^{38}$. Preparado mediante un proceso intenso de consulta, el informe del año 2000 afirma que la pobreza es una negación de los derechos humanos y una usurpación de la libertad, y que integrar los derechos humanos en

36 «Human Rights and Development: The Role of the WorldBank» («Desarrolloy derechos humanos:elpapel del Banco Mundial») (1998), que se encuentra en <http://www.worldbank.org/html/extdr/rights/>. 37 Ibid., p. 30.

38 Poverty Reduction and Human Rights. A Practice Note. Se encuentra en <http://www.undp.org/governance/ docs/HRPN_(poverty)En.pdf>. 
las estrategias para reducir la pobreza no cambia mucho «lo» que ha de hacerse sino «cómo» y «por qué» se llevan a cabo las actividades. Requiere una comprensión clara de la diferencia entre el derecho, la necesidad y la aspiración. En contraste con el Banco, que diluye los derechos humanos en la dignidad humana, el PNUD sostiene que los derechos humanos son necesarios para volver operativa la dignidad humana. Implementar los derechos humanos requiere políticas y prácticas que sean participativas, responsables y transparentes. De esta manera, «las personas pobres se convierten en actores principales y sujetos comprometidos del desarrollo ${ }^{39}$. Sin embargo, en lo que concierne a la justicia distributiva transnacional, a pesar de que el informe menciona a los sujetos de deberes ${ }^{40}$ en $_{\text {plura }}{ }^{41}$, el PNUD permanece dentro del marco del Estado, principalmente en el sentido de que su responsabilidad es la de respaldar los esfuerzos de los Estados individuales y el buen gobierno, en vez de crear nuevas obligaciones entre los Estados. Además, su modesto financiamiento reduce sus actividades al nivel de asesores, educadores y agentes del desarrollo internacional.

Dado este contraste entre el PNUD y el Banco Mundial, es por tanto importante preguntar icómo contribuiría una política mínima que considere los principios de los derechos humanos en la eliminación de la pobreza en el Banco Mundial? Claramente, esto tiene que ser predicado sobre el principio de que el desarrollo y, por ello, cualquier inversión que proclame abordar el alivio de la pobreza deben reconocer que el enfoque debe apuntar a las personas - y no a los gobiernos, al sector privado ni al PBI- Esta sería una revolución copernicana para el Banco Mundial. Requeriría que los derechos humanos sean posicionados como la meta y a la vez como el componente esencial de todas las estrategias y medios. Esto requeriría que el Banco consulte a su denominado «grupo objetivo principal», las poblaciones empobrecidas que, según afirma, desea ayudar y no tan solo a sus gobiernos. De la misma manera, los beneficios acumulados para los segmentos empobrecidos de la población se convertirían el principal criterio para evaluar un proyecto. Entre otros elementos, se desarrollarían protocolos sobre los principios y las prácticas de los derechos humanos para asegurar el derecho de todos a la no discriminación y a la participación en las decisiones que afectan sus vidas. La consulta con todos los actores es además necesaria para asegurar la observancia del principio básico de «no hacer daño». Hacer cumplir estos y otros principios de los derechos humanos, así como las metas y a la vez los medios esenciales, no es necesariamente un proceso de confrontación. Sin embargo, requeriría que el Banco desarrollase nuevos protocolos que necesiten de nuevas investigaciones y prácticas

$39 \mathrm{lbid}$. p.6. DentrodelcontextodesuProgramadeFortalecimientodelos DerechosHumanos Globales(20082011), PNUD realizará por primera vez la reunión de la Comunidad de Práctica de los Derechos Humanos Globales del PNUD para todo su personal, en la Escuela Superior del Personal de la ONU, de Turín, Italia, en octubre de 2009. Las metasson aclararel mandato y mejorarelfortalecimientode lacapacidad interna, la coordinación operativa y la gestión del conocimiento. 
para asegurar la incorporación de los estándares relevantes de los derechos humanos en sus políticas, procesos y proyectos, algo que hasta el momento ha sido evitado solícitamente.

Entre las Naciones Unidas y sus agencias, el Banco no está solo en la tarea de aliviar la pobreza, pero, a causa de su mandato sobre ella, su independencia política y sus relativos mayores recursos financieros, constituye la agencia de desarrollo de vanguardia. Dado también el tamaño y el alcance de sus proyectos, el cambio con respecto a los derechos humanos en el Banco, como en el PNUD, tendrían un impacto profundo no solamente en las agencias más pequeñas dentro y fuera de la ONU que trabajan en el desarrollo, sino también en la inversión del sector privado en los países en desarrollo.

Para avanzar en esta dirección, un obstáculo particular que enfrenta el Banco y que es reconocido por François Bourguingon en la conversación de 2005, así como por muchos críticos, es la medición de la pobreza. Sin embargo, la ausencia de una medición confiable de la pobreza acentúa las limitaciones de las formas de responsabilidad aceptadas por el Banco. Entonces, sería aun más difícil evaluar los resultados si el Banco fuera a integrar los estándares de los derechos humanos. Sería difícil determinar si estuviesen entregando algo o qué estuviesen entregando. La debilidad de dichos puntos de referencia deja al Banco en su propio mundo, capaz de ignorar las demandas y los intereses de los demás actores, de manera especial los de los pobres que proclama ayudar. Esta falta de responsabilidad frente a los seres humanos a los cuales tiene el mandato de ayudar fue evidente en un proyecto de inversión conjunta parecido al oleoducto de Chad-Camerún ${ }^{42}$, y es característico de su trabajo en el campo de la inversión extranjera directa en su totalidad ${ }^{43}$. Ha llegado el momento en que el Banco se mueva más allá de un rechazo a priori de los derechos humanos como un asunto político, para ver si la integración de los principios y prácticas de los derechos humanos en realidad no pudieran hacer de su trabajo de desarrollo, y del alivio de la pobreza en particular, algo más efectivo. Esto requiere un nuevo campo de investigación y de escrutinio.

\section{VI. ¿EXISTE UN CONSENSO INTERNACIONAL?}

Ahora es necesario revisar la definición inicial de justicia distributiva transnacional. Decía que la justicia distributiva transnacional es un campo de investigación y una práctica que aborda las obligaciones extraterritoriales de los Estados con respecto a la distribución de todas las formas de riqueza y cargas dentro de un sistema social determinado.

42 Hernández Uriz, Genoveva. «To lend or not to Lend: Oil, Human Rights aand the World Bank's Internal Contradictions". Harvard Human Rights Journal, 14, 2001, pp. 107-231. GouLD, John A. y Mathew S. WinTERS. "AnObsolescingBargain in Chad:ShiftsinLeveragebetweentheGovermentandtheWorldBank». Business and Politics, 9, 2, 2007, pp. 1-34.

43 Gould y Winters. Op. cit., p. 2. 
Sin embargo, la evidencia establecida arriba identifica una dimensión faltante, en especial el papel de facto creciente de las instituciones internacionales como agentes de la justicia distributiva. Pongamos junta toda la evidencia.

Con respecto a la existencia de una obligación en la justicia distributiva transnacional:

1. El Derecho internacional requiere de sistemas que promuevan los derechos humanos a nivel global, incluido el derecho al desarrollo de los Estados, los pueblos y los seres humanos individuales. La responsabilidad del alivio de la pobreza no se limita a la de los Estados individuales con respecto a quienes están dentro de su territorio ${ }^{44}$.

2. En el caso de abusos serios a los derechos humanos, la ley internacional reconoce la legitimidad de la acción por parte de otras naciones para remediar las violaciones serias dentro del territorio de otra nación ${ }^{45}$.

3. El Derecho internacional incluso hace que dichas acciones (prevención y castigo) sean obligatorias ${ }^{46}$.

4. Es posible introducir una legislación y sanciones que gobiernen la justicia distributiva transnacional ${ }^{47}$.

5. La soberanía nacional y los límites de los Estados podrían limitar la realización de los derechos humanos, pero la demanda y la obligación continúan, lo que toca a la comunidad internacional.

6. A pesar de que aún existe un impasse político sobre si los Estados más ricos tienen obligaciones frente a los Estados más pobres con respecto a la justicia distributiva transnacional, las organizaciones internacionales no están exentas del régimen de los derechos humanos.

Con respecto a cumplir la obligación:

1. La pobreza mundial es una preocupación para los gobiernos, la sociedad civil, las organizaciones internacionales y los académicos, si bien por distintas razones.

2. Dada la experiencia con la ineficacia de las obligaciones de la Convención Internacional para la Prevención y la Sanción del Crimen de Genocidio, y las asimetrías políticas y económicas entre los Estados del mundo, la acción concertada entre ellos 
bajo la forma de un tratado sobre el derecho al desarrollo es poco probable en un futuro previsible. Ante su ausencia, los roles de consulta y de desarrollo de otro tipo de las principales organizaciones internacionales, tales como el PNUD, UNICEF y el Banco Mundial, requieren un mayor escrutinio de sí mismos y con respecto a los derechos humanos.

3. Dado el principal mandato autoatribuido del Banco Mundial de aliviar el hambre, así como su posición única con respecto a las políticas y programas de inversión, su rechazo a integrar los derechos humanos internacionales en sus políticas y prácticas debería ser estudiado para ver si está socavando la misión central del Banco.

4. Para evitar relaciones adversas entre las organizaciones internacionales y los Estados, se requieren investigaciones sobre nuevas políticas y diálogos con el fin de estudiar las relaciones tanto exitosas como no exitosas y las nuevas formas para proteger los derechos e intereses de las poblaciones privadas de sus derechos civiles.

El examen de las distintas líneas de pensamiento con respecto al Derecho internacional y a la justicia distributiva transnacional muestra un movimiento decidido en los últimos cincuenta años. Si bien existe un impasse con respecto a que los Estados admitan las obligaciones frente a otros Estados, pueblos e individuos, la necesidad de compartir recursos comunes fuerza a las agencias intergubernamentales a desarrollar nuevos principios y prácticas para compartir la riqueza común. Entre estos principios, se encuentran los derechos humanos internacionales. A causa de su poder económico y político, dos agencias capaces de tener un impacto sustancial en el alivio global futuro de la pobreza son el Banco Mundial y la OMC. El desafío inmediato y de largo plazo para la comunidad de los derechos humanos es asegurar que ambos se tornen responsables frente a todos los actores.

\section{LOS DERECHOS \\ HUMANOSY \\ LA JUSTICIA \\ DISTRIBUTIVA

